------ Raf. J. Sci., Vol. 24, No.4 pp. 1-12, 2013------

\title{
Role of Green Tea Extract in Reducing Pathological Changes of Induced Diabetes Mellitus in Rats
}

\author{
Kamal A. Khidir Sarmad R. Kareem Ismail S. Kakey \\ Faculty of Science and Health \\ University of Koya
}

(Received 12/6/2012; Accepted 18/3/2013)

\begin{abstract}
Thirty male albino rats were used to investigate the effect of green tea extract on pancreas, renal and hepatic histological parameters in alloxan induced diabetes mellitus.

The animals were randomly distributed into five groups of six animals in each group. The first group was regarded as normal healthy control, the second group was regarded as diabetic control, the third group was treated with insulin, the fourth group was treated with green tea extract, $50 \mathrm{mg} / \mathrm{kg}$ body weight (GTE50), and the fifth group was treated with GTE100.

This study showed that functionally diabetes related organs such as pancreas, kidney and liver showed diabetes related pathological changes and these revealed a noticeable tendency for reversion to normal after treatment with green tea extract.
\end{abstract}

Keywords: rat, green tea, alloxan, diabetes.

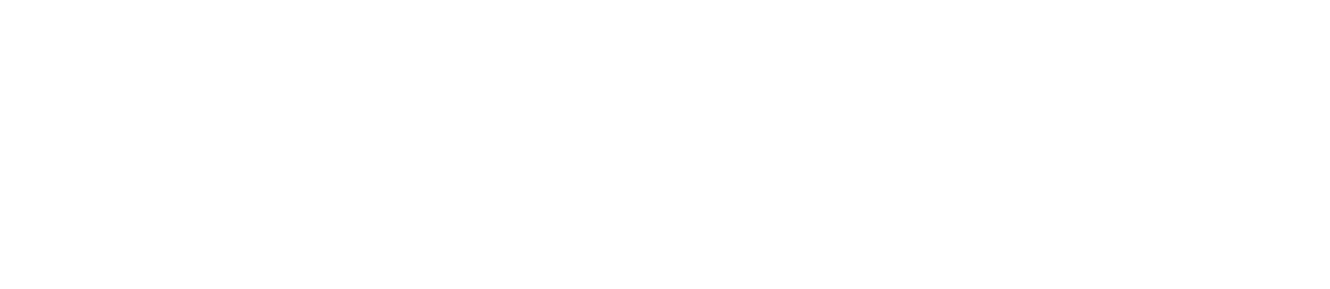

في هذه الدرلسة مق لستخدلم ثلاثن من نكور الجرذان البيض للتحري عن تأثير مستخلص الماي الأخضر

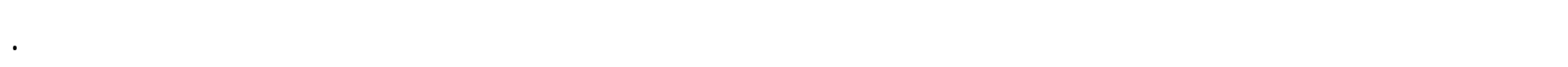

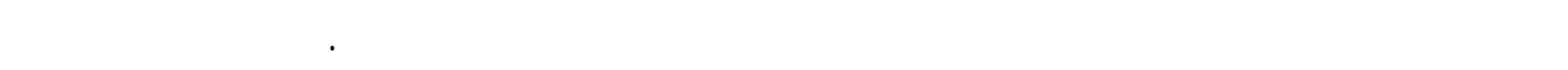

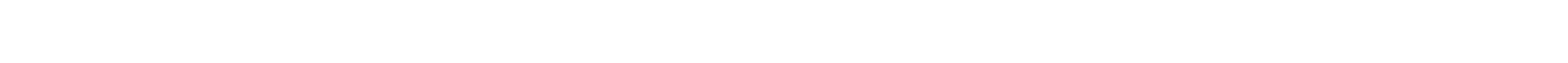

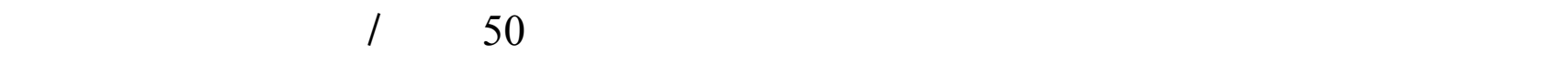

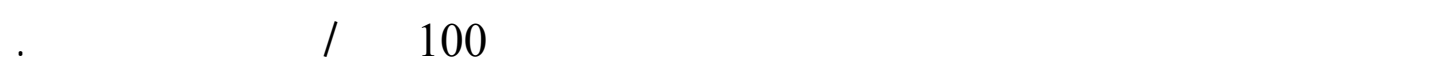

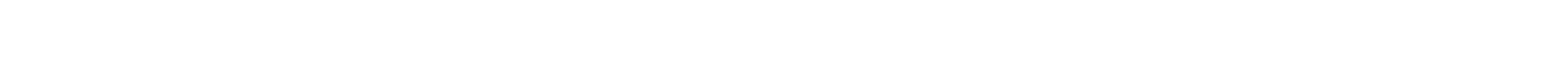
مرضية نسجية وان هذه التغييرات أظهرت تهسنا واضخاء بعد المعلملة بمستخلص الماص الثاي الأخضر. 


\section{INTRODUCTION}

Diabetes mellitus (DM) is an increasingly common, potentially devastating, expensive, treatable, but incurable lifelong disease. The world health organizations (WHO) estimat that more than 220 million people worldwide have diabetes and this number is likely to be more than double by 2030 (WHO, 2009). DM is associated with a number of chronic complications including nephropathy, neuropathy, retinopathy, and cardiovascular disorders (Mahdi et al., 2003).

Many hypoglycemic agents, such as the biguanides and sulfonylureas, are used alone or together with insulin to treat this disease, however these medications can cause serious side effects, motivating a search for safer, more efficacious agents to control diabetes (Huang et al., 2005).

Studies showed that numerous extracts obtained from plants are effective in reducing glycemia, causing fewer side effects and with lower cost than the usual antidiabetic agents (Sohn et al., 2010). The majority of the plants that are used in popular medicine for treatment of DM have been shown to possess biologically active chemical constituents such as alkaloids, flavonoids, phenolic substances, and other constituents, that can be used as new hypoglycemic agents (Negri, 2005).

The polyphenols found in green tea are more commonly known as flavonols or catechins have demonstrated significant antioxidant, anticarcinogenic, anti-inflammatory, thermogenic, and antimicrobial properties in numerous human, animal, and In vitro studies (Alschuler, 1998).

Green tea catechins are hypothesized to help protect cells against damaging effects of reactive oxygen species by contributing, along with antioxidant vitamins $\mathrm{C}$ and $\mathrm{E}$ and enzymes superoxide dismutase and catalase, to the total antioxidant defense system (Abdel-Raheim et al., 2009).

It is reported that oxidative stress is a contributor in the development and progression of $\mathrm{DM}$ and its complications. Several mechanisms can contribute to the increased oxidative stress in the diabetic patients, especially the chronic exposure to hyperglycemia (Davi et al., 2005). Hyperglycemia can lead to an elevated reactive oxygen species (ROS) production by respiratory enzyme chains in mitochondria (Nishikawa and Araki, 2007), formation of advanced glycation end-products (AGEs) (Monnier, 2003), and imbalance of glutathione redox status (Maritim et al., 2003).

\section{Pathological changes of Diabetes Mellitus \\ Pancreas}

Histological studies using pancreas specimens from patients with Insulin Dependent Diabetes Mellitus (IDDM) demonstrated that $\beta$-cell mass is reduced by $70-80 \%$ at the time of diagnosis, and beta cells are the target of autoimmune assault and that apoptosis is the major form of beta-cell death, macrophages are found to be the predominant infiltrating immune cells during the early stage of insulitis together with CD4+ and CD8+ lymphocytes, natural killer cells and $\beta$ - cells (Kumar et al., 2005).

Non insulin dependent DM is characterized by combination of insulin resistance and $\beta$ cell dysfunction, a $25-50 \%$ reduction in beta-cell mass is found at the time of diagnosis, the 
remarkably high level of beta-cell loss could result from either an impaired proliferative capability or an elevated rate of cell death (Maedler, 2008).

\section{Liver}

The liver is a central and essential organ related to DM, it performs several important functions, and it maintains glucose, fat and amino acid homeostasis (Souhami and Moxham, 1997).

Diabetes related complications in liver include, nonalcoholic fatty liver disease (NAFLD), cirrhosis, hepatocellular carcinoma, and acute liver failure, patients with DM have a high prevalence of liver disease, and numerous studies have confirmed a fourfold increased prevalence of hepatocellular carcinoma in patients with DM, as well as an increased prevalence of diabetes in patients with hepatocellular carcinoma (El-Serag et al., 2004).

\section{Kidney}

The most important glomerular lesions seen in IDDM are capillary basement membrane thickening, diffuse mesangial sclerosis, and nodular glomerulosclerosis, the glomerular capillary basement membranes are thickened throughout their entire length, but lesions can also be seen in the tubular structures and the surrounding tissue (Perrin et al., 2006). The disease advances at an individual rate over the course of several years, but ultimately most of the glomeruli will be destroyed and the patients will suffer from insufficient filtration ability (Bloomgarden, 2008).

Renal atherosclerosis and arteriolosclerosis constitute part of the macrovascular disease in DM; however, the changes in the arteries and arterioles are similar to those found throughout the body. (USRDS, 1999).

Pyelonephritis, both the acute and chronic forms of this disease occur in nondiabetics as well as in diabetics, but are more common in diabetics than in the general population, one special pattern of acute pyelonephritis, necrotizing papillitis (or papillary necrosis), is much more prevalent in diabetics than in nondiabetics (Kumar et al., 2005)

The aim of this study is to investigate the effectiveness of the green tea extract in the reduction of pathological changes of alloxan induced diabetes on rat pancreas, liver and kidney.

\section{MATERIALS AND METHODS}

Thirty male albino rats were used in this experiment. The animals were housed under standard laboratory conditions (12 hrs. light: $12 \mathrm{hrs}$. dark photoperiod, $22 \pm 2 \mathrm{C}^{\circ}$, with free access to food and water.

Aqueous green tea extract was prepared by dissolving fifty grams of mortar crushed green tea leaves in $500 \mathrm{ml}$ of distilled water, after boiling for (20) minutes, the extract was left standing for one hour till cooling. (Zhang et al., 2004).

The extract was filtered then centrifuged at $3000 \mathrm{rpm}$ for 15 minutes, the supernatant has been concentrated by rotary evaporation, and then the dried aqueous extract was dissolved in normal saline and stored at $-20{ }^{\circ} \mathrm{C}$ as the stock solution of the extract. In stock solution two doses of green tea extract $(50,100) \mathrm{mg} / \mathrm{kg}$ body weight were prepared.

Diabetes mellitus was induced in rats using diabetogenic substance alloxan monohydrate (Sigma-Aldrich Corp, St. Lous, MO, USA) by subcutaneous injection of freshly prepared 
solution of alloxan $(100 \mathrm{mg} / \mathrm{kg})$ body weight in $24 \mathrm{hrs}$ fasting animals.

One month later, rats with blood glucose more than $200 \mathrm{mg} / \mathrm{dl}$ were considered as diabetic and the animals were divided into 5 groups (6 rats in each):

Group I-normal control: rats of this group received tap water and normal food.

Group II-diabetic control: rats of this group received tap water and normal food.

Group III-insulin treated diabetic group: rats of this group received 6 units insulin per rat per day, 2 units every eight hours. The insulin was injected intraperitoneally by using insulin syringe.

Group IV-green tea extract $(50 \mathrm{mg} / \mathrm{kg})$ treated diabetic group: rats of this group received $50 \mathrm{mg} / \mathrm{kg}$ b.w. of green tea extract.

Group V-green tea extract $(100 \mathrm{mg} / \mathrm{kg})$ treated diabetic group: rats of this group received $100 \mathrm{mg} / \mathrm{kg}$ b.w. of green tea extract.

The extract was administered once per day by gavage needle for twenty eight days. After (28) days of the treatment, then the animal scarified and pancreas, liver, and kidney were harvested and immediately fixed in $10 \%$ formalin, washed with tap water, dehydrated through a series of ethanol concentrations, cleared by xylol, embedded in paraffin, sectioned by microtome at 5 micron thickness and stained with Hematoxylin and Eosin. (Bancroft and Gamble, 2008).

All sections examined and photographed by Motic digital microscope (Motic Corp, DMWB series, China).

\section{Pancreas}

\section{RESULTS}

In alloxan induced diabetes, pancreas showed the distortion of exocrine pancreas and inflammatory cell infiltration. Insulin had a relative protective role for islets of Langerhans with the effect on the exocrine portion. GTE100 treated rats, showed marked reduction in islets vascular congestion and the severity of inflammatory infiltration, despite the fact that the cellularity of islets of Langerhans was still reduced (Figs. 1 and 2).

\section{Kidney}

Diabetes showed marked histological changes in rat kidneys deposition of proteinaceous material, glomerular capillary dilation, tubular dilation and interstitial hemorrhage.

Insulin therapy relatively protected the glomeruli, despite tubular dilation and interstitial hemorrhage. GTE elicited a protective effect to the kidney despite some tubular dilation and necrotic changes and higher dose of GTE (GTE100) produced a better renal protective effect for both glomeruli and tubules (Fig. 3, 4, 5 and 6). 

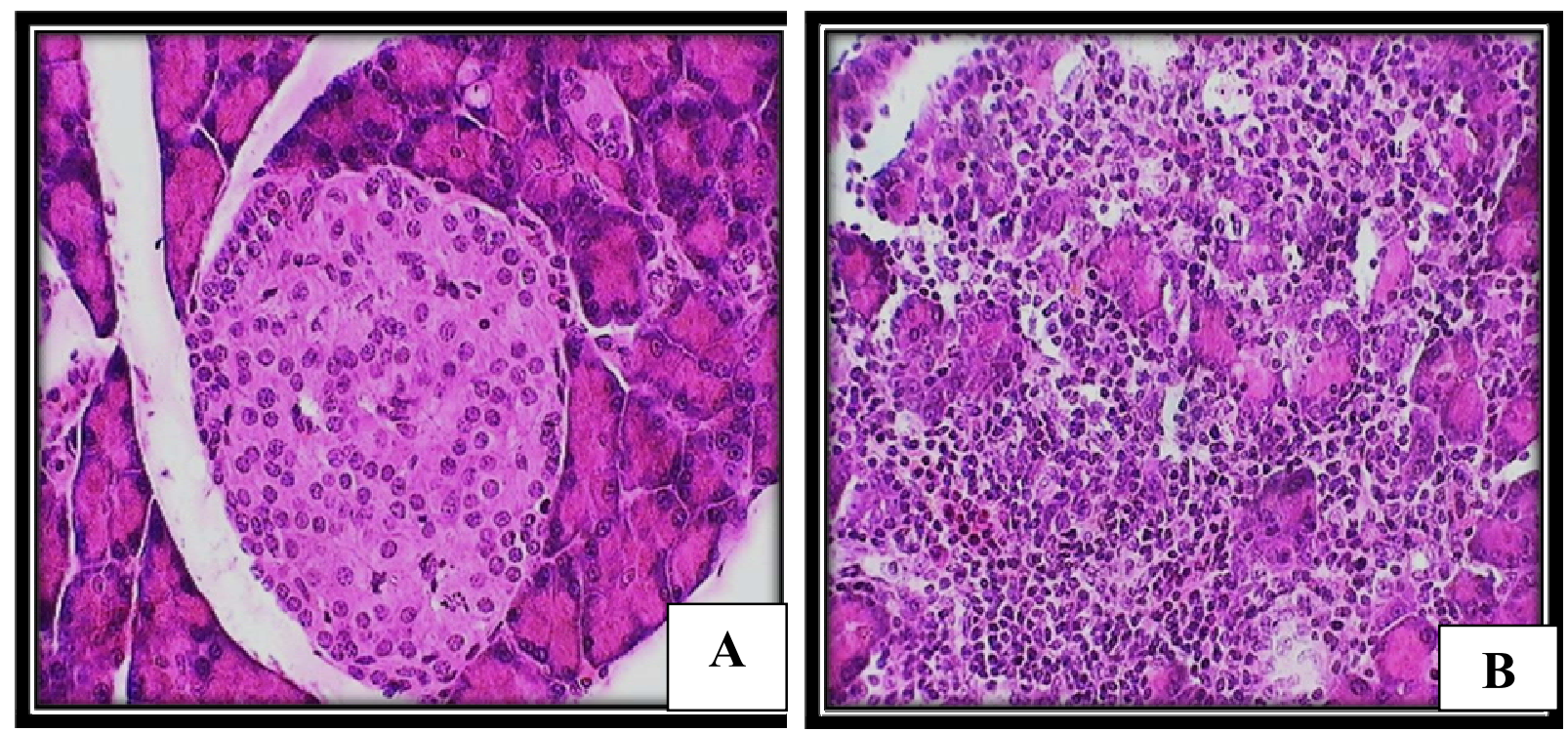

Fig. 1: Rat pancreas: A, normal islet of langerhans and surrouding exocrine pancreas; B,Untreated diabetes (control) pancreas, showed distorted exocrine pancreas with marked chronic inflammatory cell infiltration. (H and E. 400X)
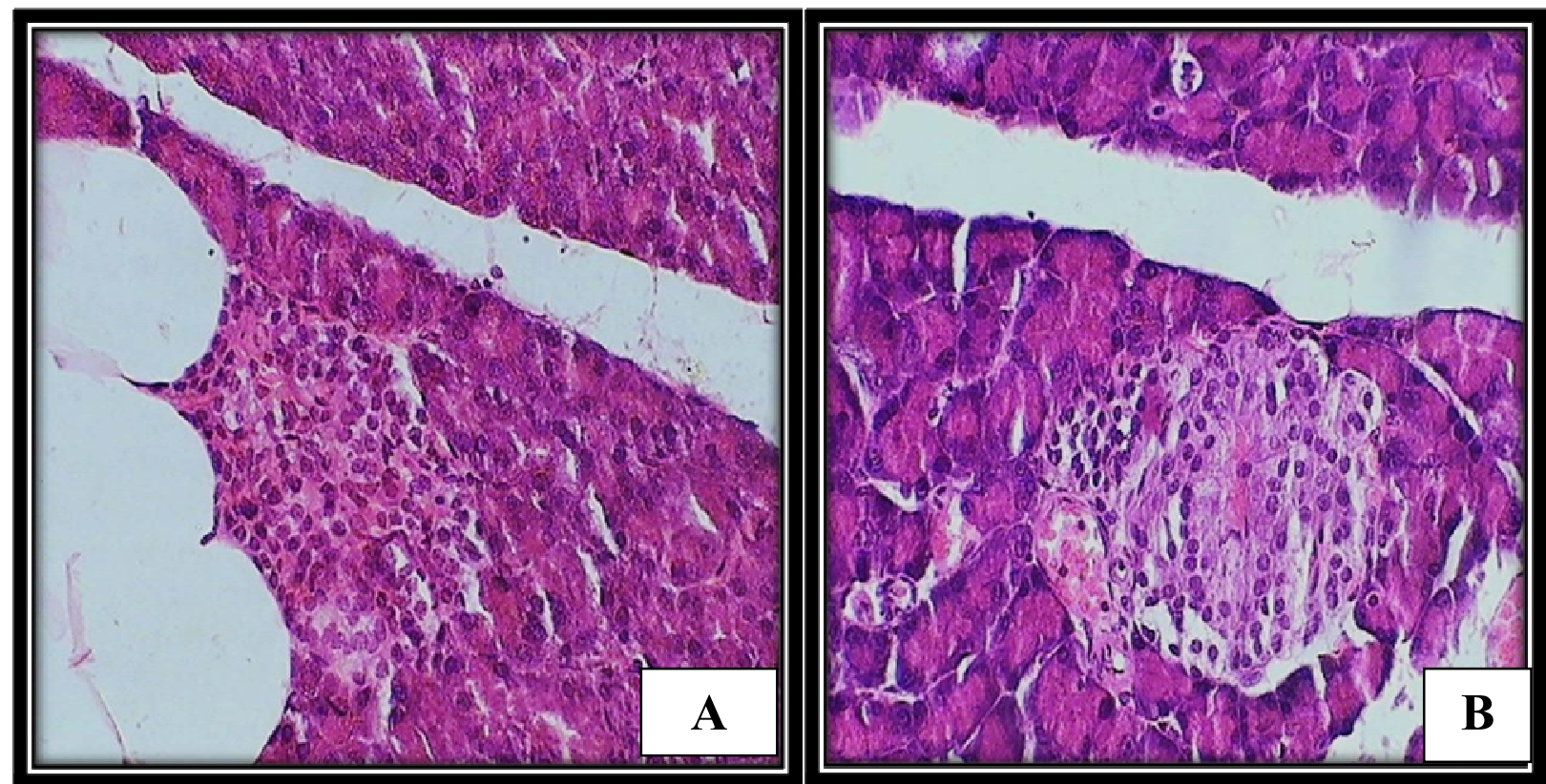

Fig. 2: Rat pancreas: A, insulin treated rat, showed relatively normal islet of langerhans and mild distortion of exocrine pancreas; B, GTE100 treated rat pancreas, showed cellularity in Islets of Langerhans is reduced and vascular congestion (Hand E. 400X). 

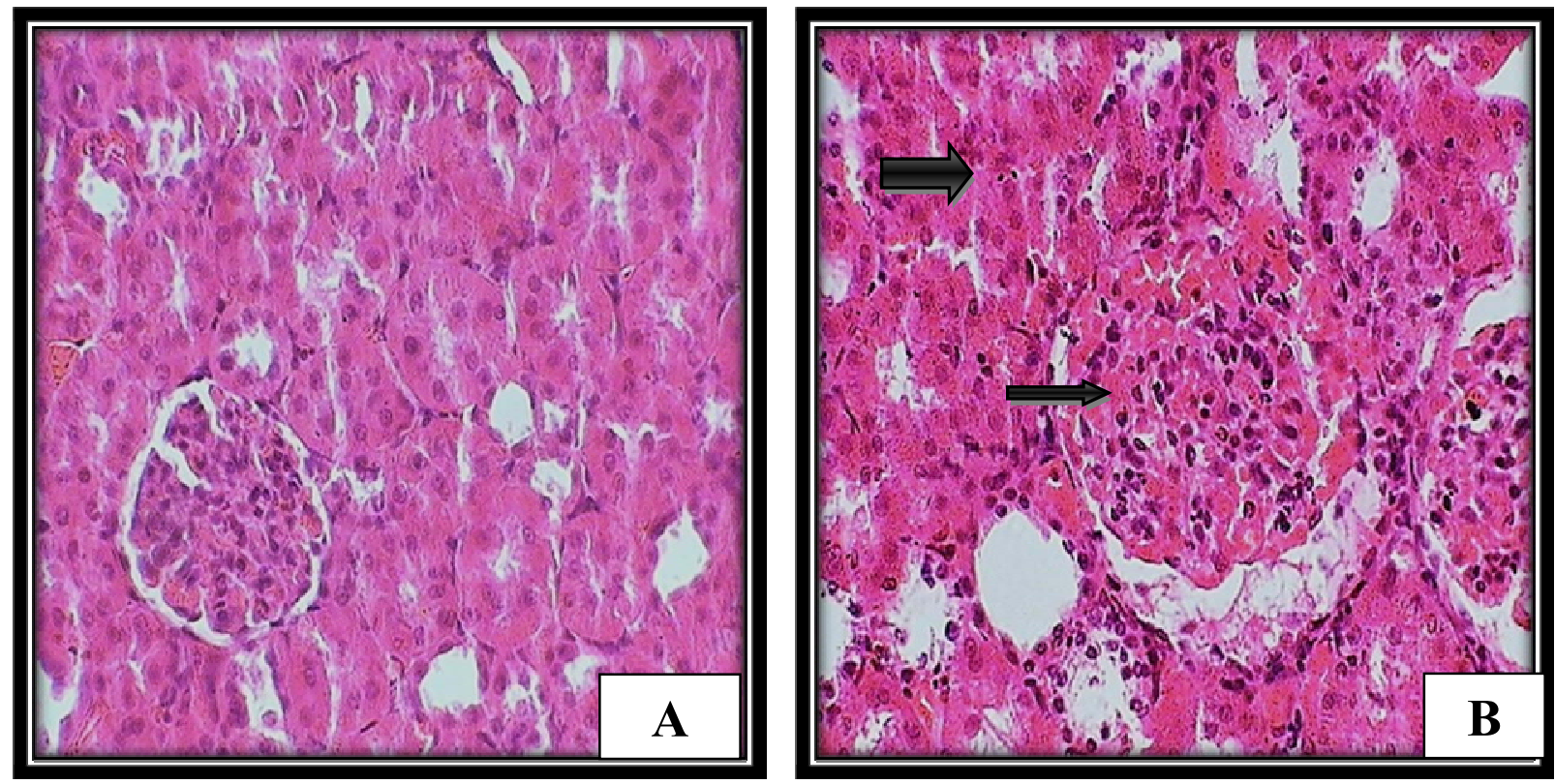

Fig. 3: Rat Kidney: A, normal glomerulus and tubules; B, diabetic rat kidney, deposition of proteinaceous material (thin arrow) and capillary dilatation, tubular dilatation and focal necrotic changes (thick arrow). (Hand E. 400X).
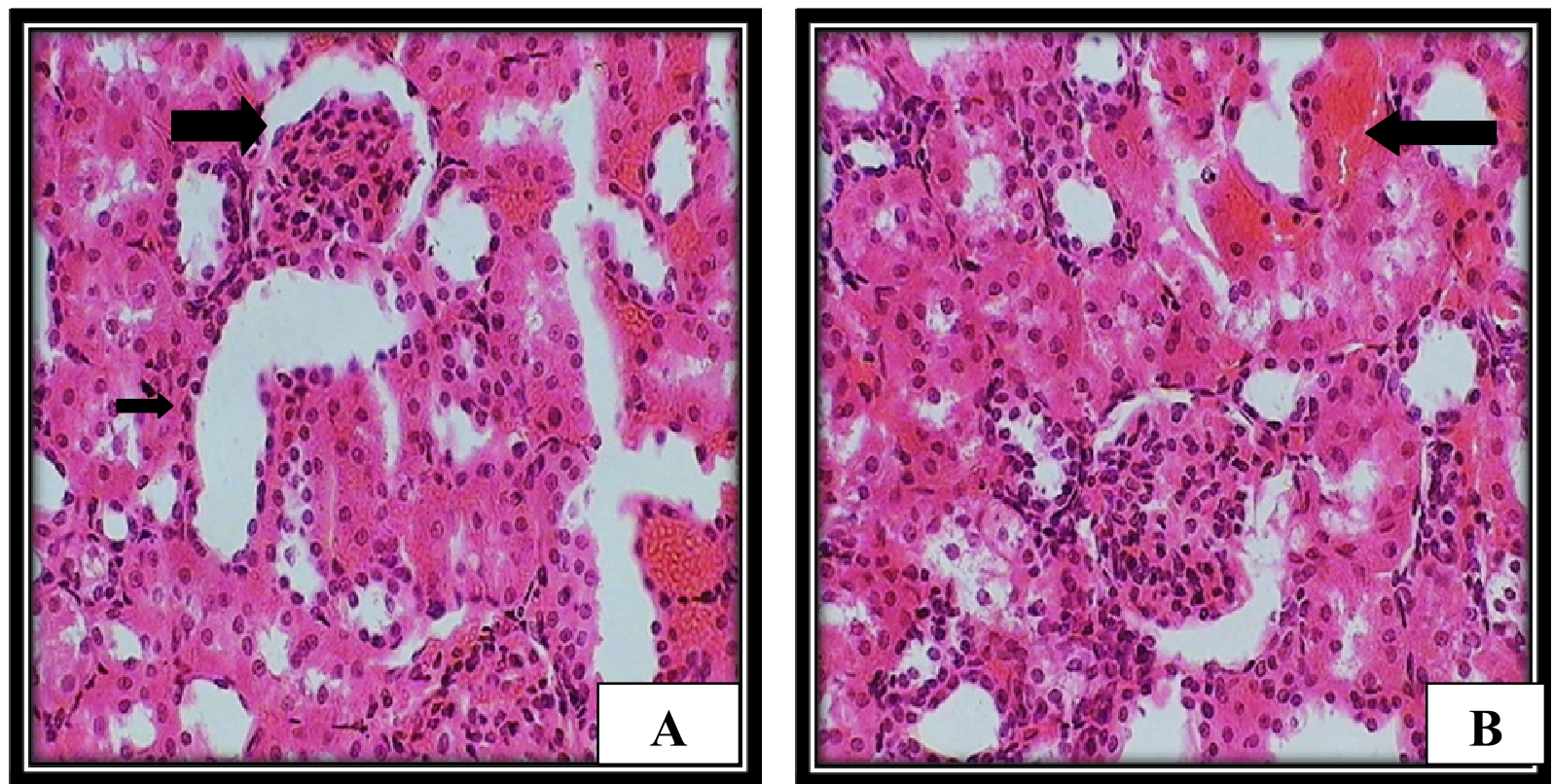

Fig. 4: Rat kidney: A, diabetic changes with mild glomerular shrinkage (thick arrow) and tubular dilatation (thin arrow); $B$, insulin was treated with tubular dilation and interstitial hemorrhage . (H and E. 400X). 


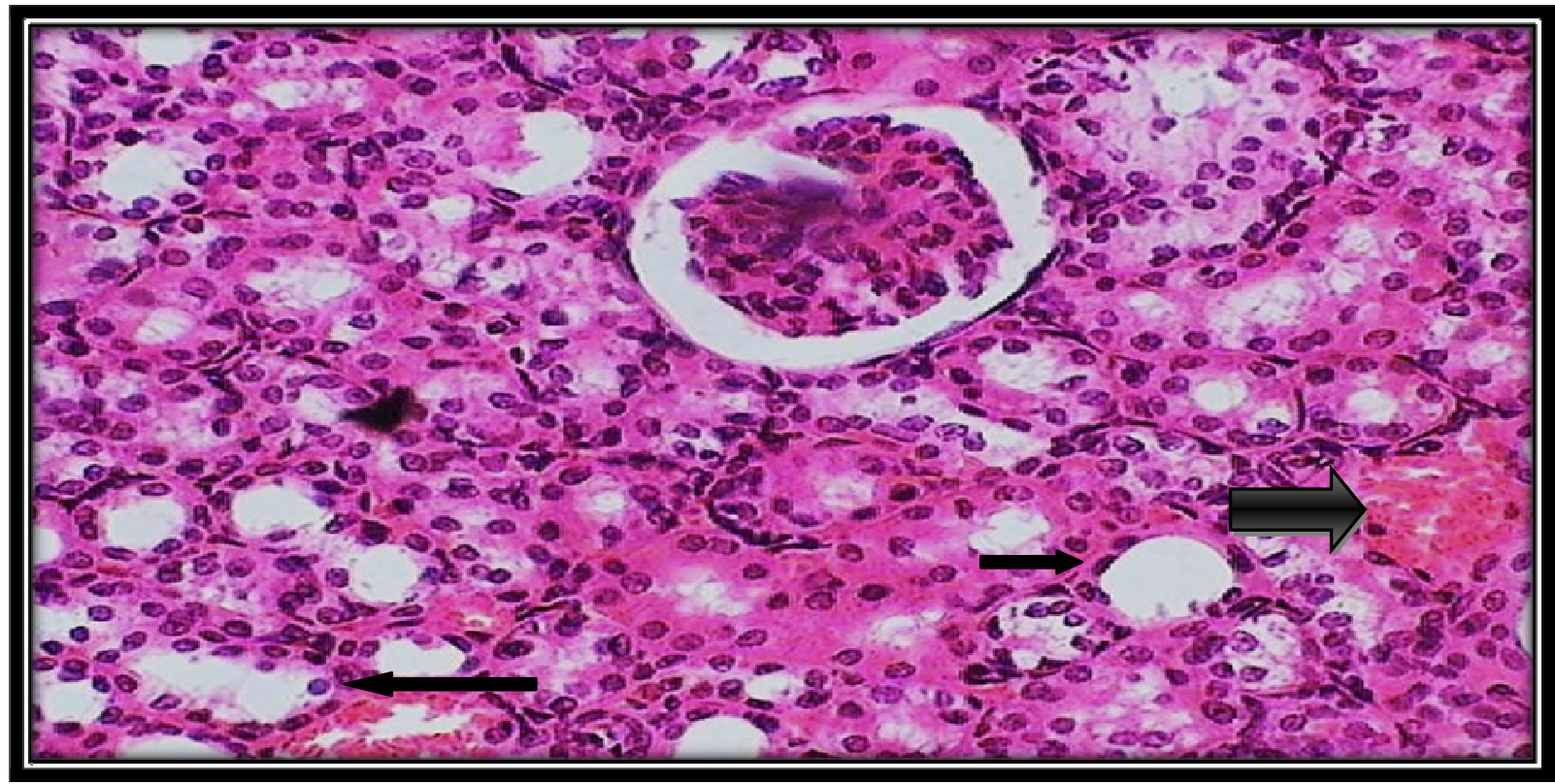

Fig. 5 : Rat kidney : GTE50 treated, nearly normal looking glomerulus, despite mild tubular dilataion(thin arrows) and focal hemorrhage (thick arrow). (H and E.400X).

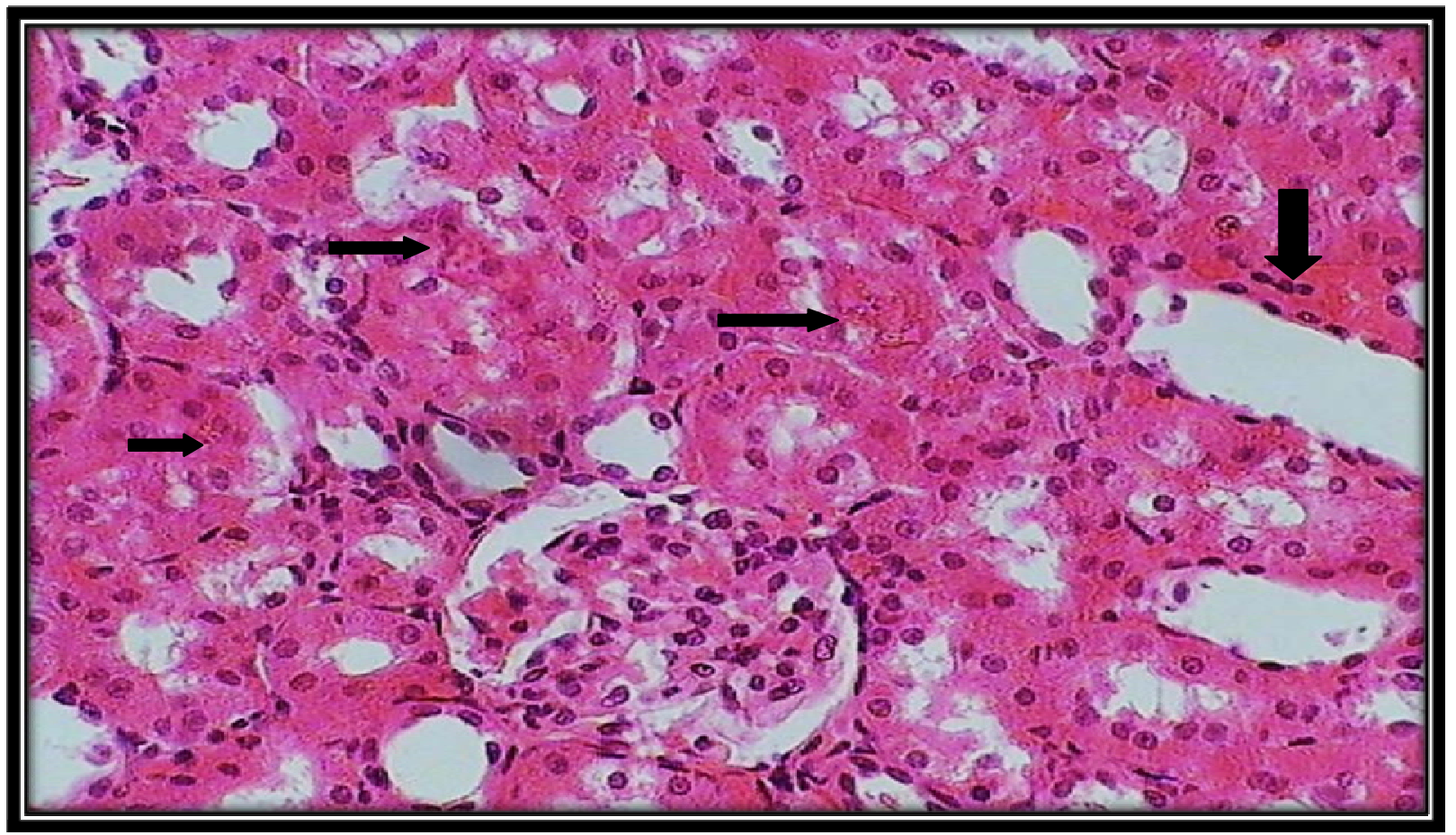

Fig. 6: Rat kidney :A, GTE100, showed normal looking glomerulus and some tubules show diltation (thick arrow)and focal necrotic changes in tubular epithelial cells(thin arrows). (Hand E.400X). 
Liver

Diabetes induced a subtle histological effect manifested as mild disruption of hepatocytes plate arrangement, focal hepatocytic necrosis, and mild focal interstitial and perivascular inflammatory cell infiltration. Insulin relatively preserved hepatic arrangement, but GTE showed a normal hepatocyte arrangement despite mild vascular congestion (Fig. 7, 8, and 9).
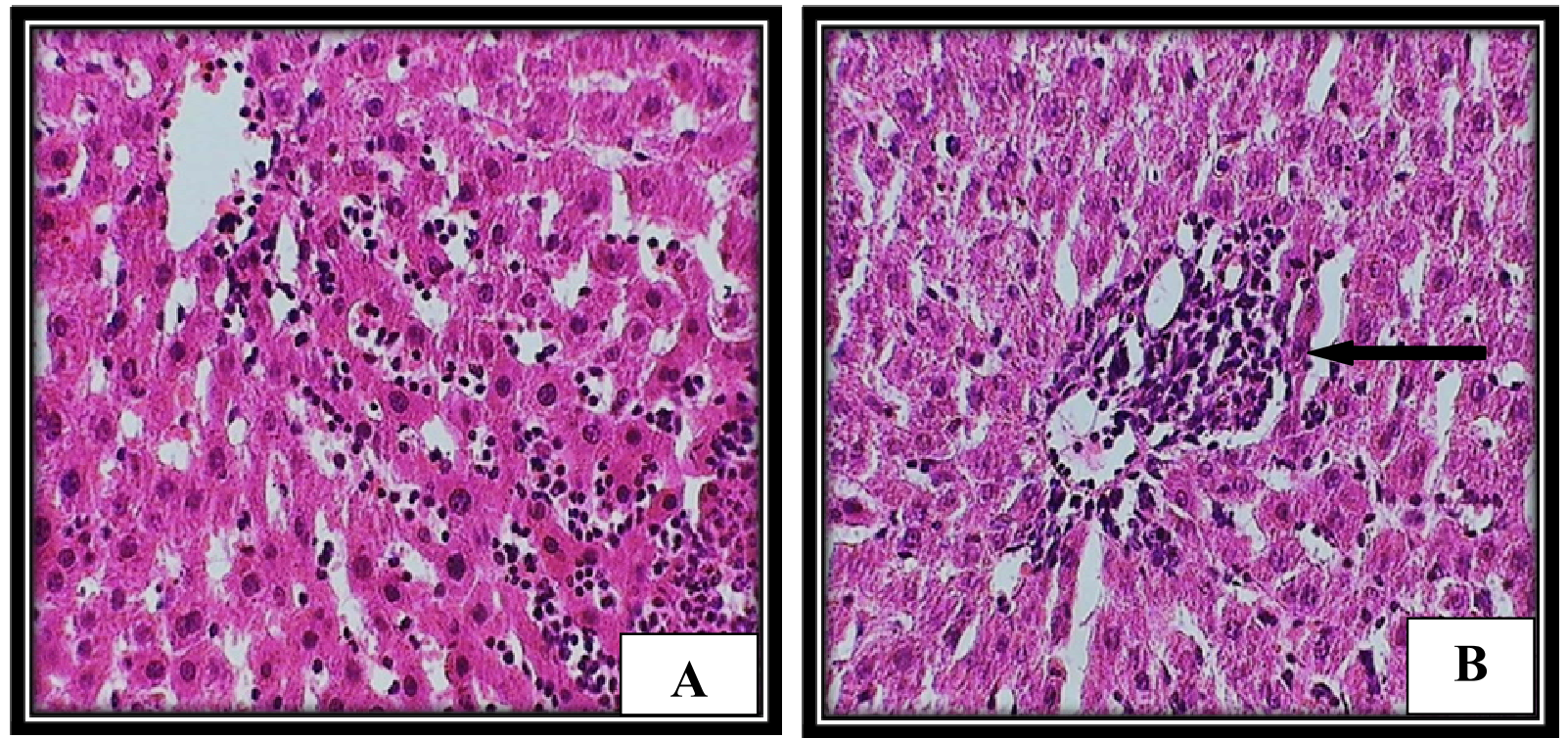

Fig. 7: Diabetic control rat liver: A, showed mild disruption of hepatocytes plates' arrangement and focal inflammation; $B$, necrotic hepatocytes, portal lymphocytic infiltration (HandE.400X).

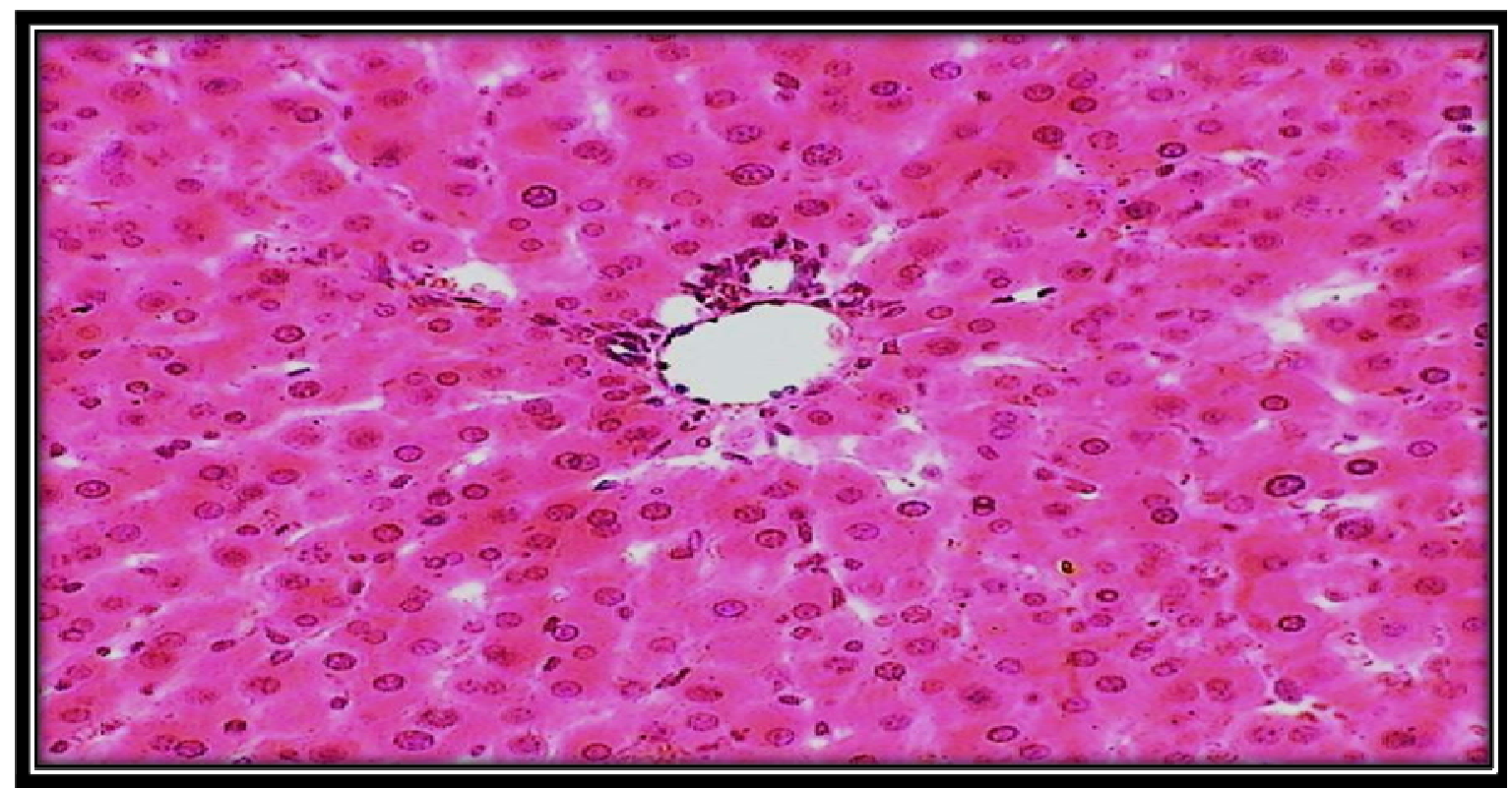

Fig. 8: Rat liver: insulin treated, showed a portal tract and focal heptocyte necrosis. (HandE.400X) 


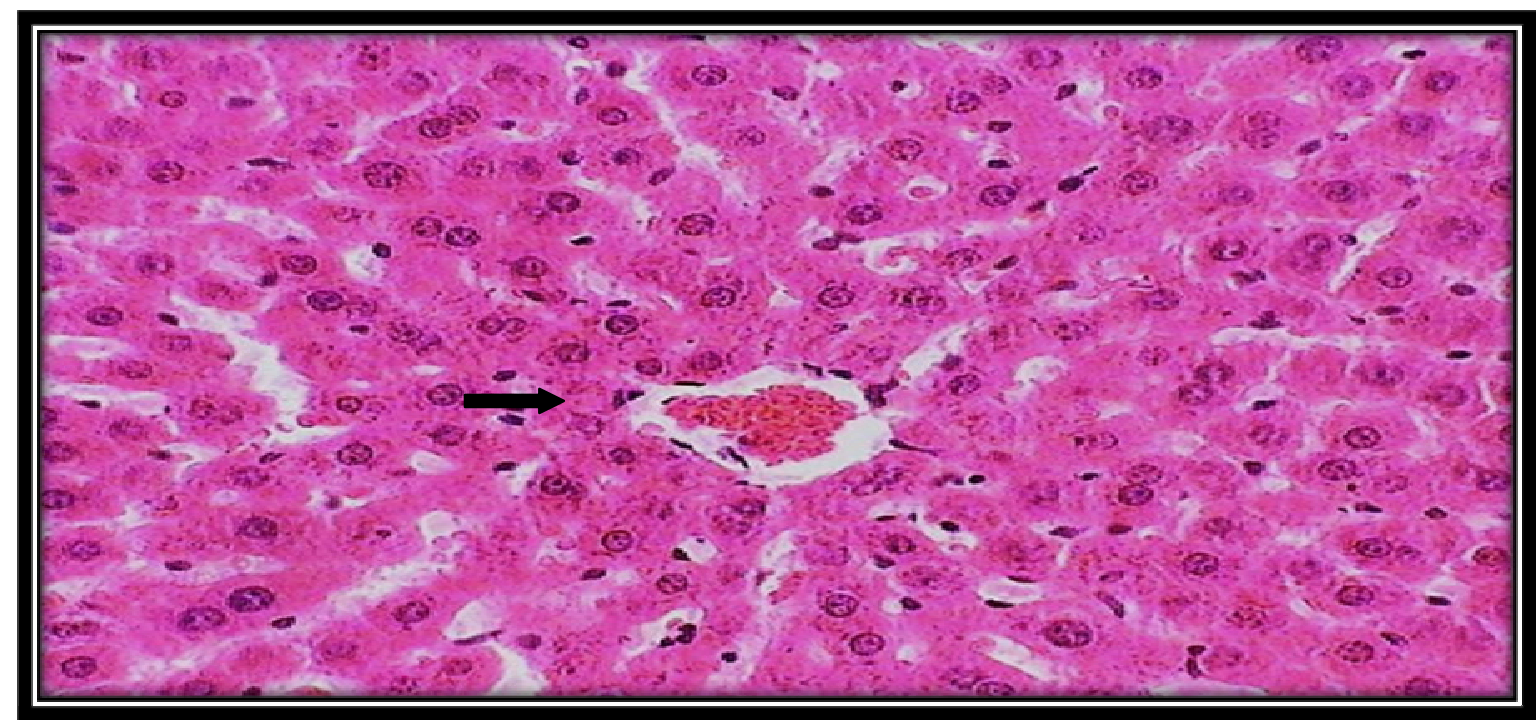

Fig. 9: Section from GTE100 treated rat liver, showed nearly normal hepatocyteplates and mild central vein cogestion (arrow). (H and $\mathrm{E} 400 \mathrm{X}$ )

\section{DISCUSSION}

Wolfram et al., (2006) demonstrated that green tea epigallocatechin gallate possesses pronounced anti-diabetic efficacy in preclinical models of type 2 diabetes mellitus, which is at least partially mediated through reducing hepatic glucose production and enhancing the pancreatic function.

A study by Karaca et al., (2010) showed, green tea extract significantly increased levels of serum insulin in the diabetic rats, and green tea extract(combined with ginseng roots) protected the cells in the islets of Langerhans.

The Diabetes Control and Complications Trial Research Group (1993) has elucidated that hyperglycemia is directly linked to diabetic microvascular complications, particularly in the kidney; therefore glycemic control remains the main target of therapy.

In diabetic nephropathy in group II (diabetic control) rats in this study there is capillary dilation, and dilated renal tubule. Similar structural changes in kidney have been reported by Vlassara et al., (1994), and they speculated that, these structural changes may be directly influenced by advanced glycation end-products (AGEs) through excessive cross-linking of matrix molecules in a receptor independent way. Green tea extract helped in amelioration of renal diabetic changes mainly through the correction of oxidative stress as shown in study by (Pedraza-Chaverri et al., 2003).

Histological examinations indicated that the liver of diabetic control male rats exhibited mild disruption of hepatocytes, focal inflammation, necrotic hepatocytes, and perivascular lymphocytic infiltration although advanced hepatic pathological changes were not seen in this study (Fig. 7).

Treatment of alloxan-induced diabetic rats with green tea extracts $(50,100 \mathrm{mg} / \mathrm{kg})$ resulted in apparent amelioration of most hepatocytes and decreased vascular congestion (Fig. 8 and 9). 
Das et al., (2005) study has shown that black tea extract (BTE) supplementation has the ability to prevent hepatocellular damage in rats receiving ethanol with or without a high-fat diet, and to restore the activity of antioxidant enzymes, reduce the generation of free radicals, lipid peroxidation. Moreover, black tea theaflavins has the ability to reduce hepatic lipid accumulation (Lin et al., 2007), and probably by chemical components of black tea that may stabilize the integrity of the cell membrane and keeping the membrane intact and the enzymes enclosed through scavenging free radicals (Oyejide and Olushola, 2005). Thus, the hepatoprotective effect of green tea extracts (GTE50, GTE100) found in the present study may be due to inhibition of the oxidative stress, induced by alloxan, by increasing cellular antioxidant capacity and reducing membrane lipid peroxidation.

Some researchers reported that, green tea extract reduce cholesterol synthesis in liver (Bursill et al., 2007) and decrease the severity of liver injury in association with lower concentration of lipid peroxidation (Chen et al., 2004).

\section{REFERENCES}

Abdel-Raheim, M.A.M.; Enas, A.H.; Khaled, A.E. (2009). Effect of green tea extract and vitamin C on oxidant or antioxidant. Indian J. Clin. Biochem., 24(3), 280-287.

Alschuler, L.(1998). Green tea: healing tonic. Am. J. Natur. Med., 5, 28-31.

Bancroft, J.D.; Gamble, M. (2008). "Theory and Practice of Histological Techniques". 6th ed., Churchill Livingstone, Edinburgh. pp.126-127.

Bloomgarden, ZT. (2008). Diabetic nephropathy. Diabetes Care., 31, 823-827.

Bursill, C.A.; Abbey, M.; Roach, P.D. (2007). A green tea extract lowers plasma cholesterol by inhibiting cholesterol synthesis and upregulating the LDL receptor in the cholesterolfed rabbit. Atherosclerosis., 193, 86-93.

Chen, J.H. ; Tipoe, G.L.; Liong, E.C.; So. H.S.; Leung, K.M.; Tom, W.M. (2004). Green tea polyphenols prevent toxin-induced hepatotoxicity in mice by down-regulating inducible nitric oxidederived prooxidants. Am. J. Clin. Nutr., 80, $742-51$.

Das, D.; Mukherjee, S.; Mukherjee, M. (2005). Aqueous extract of black tea (Camellia sinensis) prevents chronic ethanol toxicity. Curr. Sci., 88, 952-961.

The Diabetes Control and Complications Trial Research Group (1993). The effect of intensive treatment of diabetes on the development and progression of long-term complications in insulin-dependent diabetes mellitus. N. Engl. J. Med., 329, 977-986

El-Serag, H.B; Tran, T.; Everhart, J.E.; Kaserer, K.; Fiedler, R.; Steindl, P.; Muller, C.H.; Wrba F.; Ferenci P.; Rubbia-Brandt, L.; Leandro, G.; Spahr, L.; Giostra, E.; Quadri, R.; Male, P.J.; Negro, F.; Hui, J.M.; Kench, J; Farrell, G.C.; Lin. R.; Samarasinghe, D.; Liddle, C.; Byth, K.; George, J.; Castera, L.; Hezode, C.; Roudot-Thoraval, F.; Lonjon, I.; Zafrani, E.S.; Pawlotsky, J.M.; Dhumeaux, D.; Lonardo, A.; Adinolfi, L.E.; Loria, P.; Carulli, N.; Ruggiero, G.; Day, C.P. (2004). Diabetes increases the risk of chronic liver disease and hepatocellular carcinoma. Gastroenterology., 126, 460-468.

Huang, P.H. (2005). Enhanced coronary calcification determined by electron beam CT is strongly related to endothelial dysfunction in patients with suspected coronary artery disease. Chest., 128(2), 810-5. 
Karaca, T.; Yoruk, M.; Yoruk, I.H.; Uslu, S. (2010). Effects of extract of green tea and ginseng on pancreatic beta cells and levels of serum glucose, insulin, cholesterol and triglycerides in rats with experimentally streptozotocin-induced diabetes: A histochemical and immunohistochemical study. J. American and Veterinary Advances., 9(1), 102-107.

Kumar, K.; Abbas, A.; Fausto, N. (2005). "Robbins and Cotrans Pathological Basis of Disease". 7th ed., Elsevier Inc. Philadelphia, Pennsylvania. pp. 213-226.

Lin, C.L.; Huang, H.C.; Lin, J.K. (2007). Theaflavins attenuate hepatic lipid accumulation through activating AMPK in human HepG2 cells. J. Lipid Res. 48, 2334-2343.

Maedler, K. (2008). Beta cells in type 2 diabetes - a crucial contribution to pathogenesis. Diabetes Obes. Metab. 10(5), 408-20.

Mahdi, A. A.; Chandra, A.; Singh, R.K.; Shukla, S.; Mishra, L.C. (2003). Effect of herbal hypoglycemic agents on oxidative stress and antioxidant status in diabetic rats. Indian. J. Clin. Biochem., 18,8.

Maritim, A.C.; Sanders, R.A.; Watkins, III. JB. (2003). Diabetes, oxidative stress, an antioxidants: a review. J. Biochem. Mol. Toxicol., 17, 24-38.

Monnier, V.M. (2003). Intervention against the Maillard reaction in vivo. Arch. Biochem Biophys., 419, 1-15.

Negri, G. (2005). Diabetes melito: plantas e princ1'pios ativos naturais hipoglicemiantes. Rev. Bras. Cienc. Farm., 41, 121-142.

Nishikawa, T.; Araki, E. (2007). Impact of mitochondrial ROS production in the pathogenesis of diabetes mellitus and its complications. Antioxid Redox Signal., 9, 343-53.

Oyejide, O.O. ; Olushola, L. (2005). Hepatoprotective and antioxidant properties of extract of Carmellia sinensis (black tea) in rats. Afr. J. Biotechnol., 4, 1432-1438.

Pedraza-Chaverrí, J.; Barrera, D.; Maldonado, P.D.; Chirino, Y.I.; Macías-Ruvalcaba, N.A.; Medina-Campos, O.N.; Castro, L.; Salcedo, M.I.; Hernández-Pando, R. (2004). Sallylmercaptocysteine scavenges hydroxyl radical and singlet oxygen in vitro and attenuates gentamicininduced oxidative and nitrosative stress and renal damage in vivo. BMC. Clin. Pharmacol., 4, 5-18.

Perrin, N.; Torbjornsdotter T.B.; Jaremko, G.A.; Berg, U.B. (2006). The course of diabetic glomerulopathy in patients with type I diabetes: a 6-year follow-up with serial biopsies. Kidney Int., 69, 699-705.

Sohn, E.; Kim, J.; Kim, C.S.; Kim, Y.S.; Jang, D.S.; Kim, J.S. (2010). Extract of the aerial parts of Aster koraiensis reduced development of diabetic nephropathy via antiapoptosis of podocytes in streptozotocin- induced diabetic rats. Biochem. Biophys. Res. Commun., 391, 733-738.

Souhami, R.L. ; Moxham, J. (1997). " Textbook of Medicine". 4th ed., Churchill Livingstone, Edinburgh. pp. 312-320

USRDS (United States Renal Data System) (1999). Annual Data Report. Bethesda, MD, The National Institutes of Health, National Institute of Diabetes and Digestive and Kidney Diseases. 
Vanessa, C.; Gary, W. (2004). A Review of the health effects of green tea catechins in In vivo animal models. J. Nutr., 134, 3431S-3440S.

Vlassara, H.; Striker, L.J.; Teichberg, S.; Fuh, H.; Li, Y.M.; Steffes, M. (1994). Advanced glycation end products induce glomerular sclerosis and albuminuria in normal rats. Proc. Natl. Acad. Sci. USA. 91, 11704-11708.

Wolfram, S.; Raederstorff, D.; Preller, M.; Wang, Y.; Teixeira, S.R.; Riegger, C.; Weber, P. (2006). Epigallocatechin gallate supplementation alleviates diabetes in rodents. $J$. Nutr., 136, 3512-3518.

World Health Organization. Prevalence data of diabetes worldwide. (2009). http://www.who.int/mediacentre/factsheets/fs312/en/index.html.

Zhang, G.; Matsumoto, S.; Hyon, S.H.; Qualley, S.A.; Upshaw, L.; Strong, D.M.; Reems, J.A. (2004). Polyphenol, an extract of green tea, increases culture recovery rates of isolated islets from nonhuman primate pancreata and marginal grade human pancreata. Cell Transplant. 13(2),145-52.(abstract) 